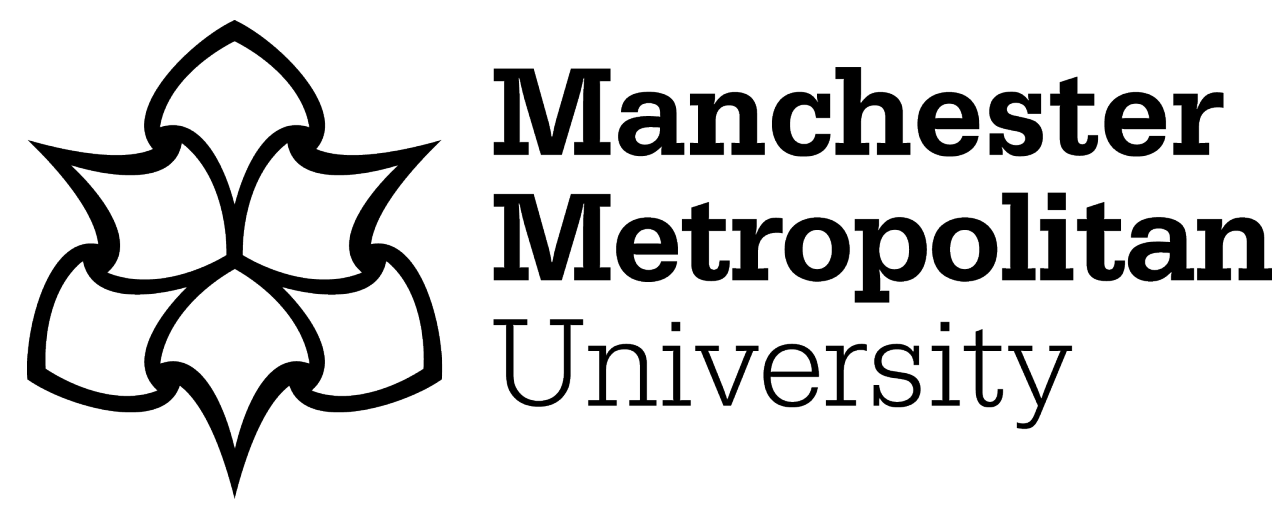

Parry, SL, Simpson, J and Lloyd, M (2017) Experiences of Therapeutic Relationships on Hospital Wards, Dissociation and Making Connections. Journal of Trauma and Dissociation, 18 (4). pp. 544-558. ISSN 1529-9740

Downloaded from: https://e-space.mmu.ac.uk/617191/

Version: Accepted Version

Publisher: Taylor \& Francis

DOI: https://doi.org/10.1080/15299732.2016.1241852

Please cite the published version 
RUNNING HEAD: Dissociative Experiences and Therapeutic Relationships on Wards

\section{Experiences of Therapeutic Relationships on Hospital Wards, Dissociation and Making Connections}

\section{Authors}

1) Dr Sarah Parry, DClinPsy - corresponding author

2) Dr Mike Lloyd, DClinPsy

3) Dr Jane Simpson, DClinPsy

\section{Acknowledgements}

Foremost, we would like to thank the inspiring ladies who generously shared their experiences, we are so grateful and thankful for your stories. We would also like to thank ESTD-UK for their guidance and the networks and individual therapists who helped inform people about this project. 
Dissociative Experiences and Therapeutic Relationships on Wards

\begin{abstract}
An interpretative phenomenological analysis sought to explore how people reporting moderate to high levels of dissociation experienced relationships with multidisciplinary hospital ward staff. Three superordinate themes were developed. Firstly, the theme Multiple Me and Multiple Them explores the instability experienced by the participants as they managed their dissociative experiences alongside many inconsistencies. Secondly, Recognising, Meeting or Neglecting Interpersonal and Care Needs, reflects upon participants' needs within therapeutic relationships. Thirdly, Between the Needs of the Internal System: navigating between "better on my own" and "someone to talk to", discusses the confusion and understanding around dissociation and the importance of working with parts, not around them. Findings suggested the current culture of some hospital wards directly influenced participants' distress, which could lead to further dissociation as a means of coping with perceived threats. Reflections upon relational complexities and developing wardbased treatment are discussed.
\end{abstract}


Dissociative Experiences and Therapeutic Relationships on Wards

\section{Experiences of Therapeutic Relationships on Hospital Wards, Dissociation and Making Connections}

Links between early trauma and dissociation (e.g. Braehler et al., 2013; Brown, Schrag, \& Trimble, 2005) and the interpersonal needs of people experiencing dissociation have been most commonly understood within attachment (see Dillon, Johnstone, \& Longden, 2012; Lyons-Ruth, Dutra, Schuder, \& Bianchi, 2006) and developmental frameworks (see Schimmenti \& Caretti, 2014). Within both theoretical frameworks, positive and mutually trusting relationships are identified as particularly important (International Society for the Study of Trauma and Dissociation ([ISSTD] 2011).

This relational need is essential in therapeutic relationships, which should ideally be "built on mutual trust, understanding and a collective knowledge" (Strachan, 2011, p.2). Through her empirical research with people experiencing higher levels of dissociation, Hirakata (2009) suggests that positive therapeutic relationships could facilitate the reconnection and integration processes with parts of the divided self. Specifically, dissociative identity disorder (DID) can be understood through the theory of structural dissociation, which proposes a division in one's personality (Nijenhuis, \& Van der Hart, 2011). Divided parts of the person can be familiar or unknown to the central personality and are usually referred to as parts, alters, self-states or personas. A possible cause of structural dissociation, which is similar to the concept of compartmentalisation dissociation (see Holmes et al., 2005), is thought to be interpersonal trauma from which there is no escape (Herman, 1992; Nijenhuis \& Van der Hart, 1999). Therefore, the importance of the therapeutic relationship and its possible role in healing the integration of parts of the self seems highly relevant for people experiencing dissociation (Gill, 2010; McAllister et al., 2001). 
Dissociative Experiences and Therapeutic Relationships on Wards

Interpersonal connections in therapeutic relationships can play an essential role in facilitating inter- and intrapersonal reconnection and wider attachment changes (Mikulincer, Shaver, \& Berant, 2013). For instance, McAllister et al. highlighted that positive relationships between people with DID and hospital staff could encourage "recovery from past trauma, social connections, resilience and safety" (2001, p.31). Additionally, McAllister et al. identified several areas of difficulty related to the navigation of boundaries, development of trust and a reliance on victim-based schemas, although highlighted further research is required.

In light of the disconnection that people who dissociate can experience from others (Hirakata, 2009), their experiences of therapeutic relationships may be particularly complex, which may be particularly multifaceted as the divided parts of the self are likely to hold different perspectives on the self and others (Nijenhuis, 2008). Specifically, exploring the first person accounts of people who dissociate could inform perceptions of dissociation and insights around interventions (Hirakata, 2009). Although it would be difficult to explore therapeutic relationships with all of a person's alters, multiple first person accounts might develop an overall perspective.

No empirical qualitative study thus far has attended explicitly to the perceptions of people experiencing dissociation concerning their perspectives on the therapeutic relationships they develop with hospital ward staff. Therefore, this interpretative phenomenological analysis (IPA) sought to explore how people reporting moderate to high levels of dissociation experienced therapeutic relationships and developed a meaningful personal narrative around their relationships with multidisciplinary hospital ward staff. 
Dissociative Experiences and Therapeutic Relationships on Wards

\section{Method}

\section{Design}

In order to explore ward-based therapeutic relationships with people experiencing dissociation, semi-structured interviews were employed. The interview schedule was used as a guide, although the participants were encouraged to lead the conversation (Pietkiewicz \& Smith, 2014), so as to preserve their perspective (Hefferon \& Gil-Rodriguez, 2011), prior to the first author's interpretations of the data.

\section{Participants}

Seven women took part in the study $($ Mage $=40.57$ years, $S D=10.34)$, to facilitate in-depth explorations of idiographic experiences. The inclusion criteria for those who took part was to have been on a UK National Health Service (NHS) ward for at least two weeks within the last two years (Frank \& Gunderson, 1990) and score at least 30 on the DES-II, indicating moderate to high levels of dissociation (Carlson \& Putnam, 1993; Moskowitz, 2004). This study was approved by an appropriate UK NHS ethics committee and the research committee of the ESTD-UK. Participants provided consent to take part and their individual preferences were discussed regarding dissociative experiences during the interview. Participants were offered compensation for their travel to the interview, although all requested to be visited by the first author at their home or alternative location nearby.

Table 1: Participant Information

\begin{tabular}{llll}
\hline Pseudonym & Age Range & DES Score & Type(s) of inpatient stay \\
\hline Amelia & $40-49$ & 65 & Numerous physical and mental health \\
& & & admissions over many years, health admission \\
& & for stroke most discussed in interview \\
\hline
\end{tabular}




\begin{tabular}{|c|c|c|c|}
\hline Ashleigh & $20-29$ & 35 & $\begin{array}{l}\text { One long-term admission, which included a } \\
\text { range of settings including a secure mental } \\
\text { health unit, an acute ward and a general mental } \\
\text { health ward }\end{array}$ \\
\hline Claire & $20-29$ & 51 & $\begin{array}{l}\text { One long-term admission discussed, including } \\
\text { an acute psychiatric ward and a neuro- } \\
\text { rehabilitation ward }\end{array}$ \\
\hline Ellie & $40-49$ & 61 & $\begin{array}{l}\text { Many admissions to physical and mental health } \\
\text { wards over a } 20 \text { year period, admission to health } \\
\text { ward most discussed in interview }\end{array}$ \\
\hline Hermione & $50-59$ & 76 & $\begin{array}{l}\text { Multiple admissions to mental health wards and } \\
\text { visits to accident and emergency departments } \\
\text { over a } 30 \text { year period }\end{array}$ \\
\hline Mel & $40-49$ & 70 & $\begin{array}{l}\text { Multiple admissions to mental health wards over } \\
\text { a } 15 \text { year period, largely acute mental health } \\
\text { wards }\end{array}$ \\
\hline Sam & $40-49$ & 88 & $\begin{array}{l}\text { Multiple admissions to mental health wards over } \\
25 \text { year period, mostly acute mental health }\end{array}$ \\
\hline
\end{tabular}

\section{Procedure}

Recruitment adverts were placed with appropriate newsletters and sent by email to therapists registered with the European Society of Trauma and Dissociation in the UK (ESTD-UK). All participants completed a consent form and the Dissociative Experiences Scale ([DES-II], Carlson \& Putnam, 1993). The DES-II is a 28-item self-report measure employing a 0-100 point Likert scale that can usually be completed in about ten minutes, with higher scores indicating higher levels of dissociative experiences. Once the DES-II was completed and scored (group $M=64.13, S D=17.16$ ), the participant and first author discussed when to conduct the interview. Interviews lasted between 38 and 103 minutes ( $M$ 
Dissociative Experiences and Therapeutic Relationships on Wards

minutes 43) and were recorded on a digital audio-recording devise, transcribed verbatim by the first author and analysed by hand using IPA.

\section{Data Analysis}

IPA aims to explore the "participant's cognitive and affective reaction" to their experiences and acknowledges there is a "chain of connection between embodied experience... and a participant's making sense of, and emotional reaction to, that experience" (Smith, 2011, p.10). Therefore, IPA was an appropriate analytical method for the sample population who may have experienced difficulties in integrating emotional and cognitive experiences.

Finally, an epistemological stance of critical realism was taken, which discerns the "essence of things from their appearance" (Losch, 2009, p.86), thus facilitating finding the nuances in the data to illustrate experiential subtleties. Epistemological and empirical discussions highlight that autobiographical accounts are based upon perception rather than fact (Bedard-Gilligan \& Zoellner, 2012), which is highly relevant due to the recognised difficulties people experiencing detachment dissociation can have in terms of autobiographical memory (Holmes et al., 2005).

Considering the context of critical realism within which the analysis was conducted (Bhaskar, 1993), the process in relation to the spheres of critical realism (the real, actual and empirical) was both a top-down process in design and expectations but a bottom-up process concerning the interpretative analysis. Prior to conducting the interviews, the authors had expectations around how trauma experiences might influence dissociation and how experiencing reactions to trauma could influence a person's sense of self. However, the individual nature of IPA meant that drawing upon information from the real and actual was not possible until the later interpretative stages of the analysis. In terms of how the spheres of 
Dissociative Experiences and Therapeutic Relationships on Wards

critical realism were perceived by the first author during the interpretative phases, the participants' sharing of information within parts of the divided self within the sphere of the real indicated the feelings of separation and detachment with the forgetting and losing of time discussed in the actual. These lived experiences were then explained explicitly within the accounts of disruptions in perception and memory, alongside difficulties concentrating, trusting, and finding consistency within the empirical.

\section{Findings and Discussion}

The findings suggest that there were both negative and nurturing factors that affected the development of interpersonal therapeutic relationships between participants and ward staff, which were influenced by intrapersonal factors.

Theme 1: Multiple Me and Multiple Them - "we [central persona and alters] have problems with change.” (Sam)

A predominant phenomenon within the data was that of participants trying to cope with the inconsistencies of the ward environment and multiple staff members, while managing their dissociation and adjusting to new experiences.

1.1: Adjusting as one self or parts - "you just get used to one place and they move you and... you have to get used to the staff again..." (Claire)

Within all the participants' accounts were statements surrounding adjusting, adapting and trying to cope with change. For the five participants with alters (Sam, Ellie, Mel, Amelia, and Hermione), this process seemed particularly complex; as Sam described "It's hard when you have different people [alters] talking to you... they [staff] think your being rude". Furthermore, Ellie experienced that her parts were responding differently to ward staff, saying that: "part of me was bemused... and another part of me was angry... that they were 
Dissociative Experiences and Therapeutic Relationships on Wards

judging me... and they didn’t actually know me at all’. It has been suggested that early disorganised attachments relating to attachment figure related traumas, leading to disorganised internal working models, can develop a perspective and experience of the self and others as unintegrated and with multiple representations (Dutra, Bureau, Holmes, Lyubchik, \& Lyons-Ruth, 2009; Liotti, 2013; Stovall-McClough \& Cloitre, 2006). This theoretical process seems relevant to the participants' accounts in that multiple-self experiences were reported, which appeared to influence participants' perception of how others may have perceived them. For instance, Hermione described how she had adapted to the ward environment through dissociation: "I go into the survival mode... all you have to do is get through your time there... Switching into perfect Hermione mode". Participants' alters could appear very separate from the main persona or more connected. Importantly, participants discussed alters as additional or separated selves, rather than metaphors for differing emotional states as was suggested by Merckelbacha, Devillyc, and Rassin (2002).

Participants described moving between wards as difficult for a range of reasons. Most apparently, establishing new relationships, managing change and adjusting to new people appeared particularly challenging. Although not explicitly stated, some of the accounts around change and new staff seemed reminiscent of mistrust and anxiety in relationships. Such relational responses have been cited elsewhere as very difficult for this client group due to previous violations of trust in childhood (McAllister et al., 2001). Ellie described how she felt unsettled when she had not been given any warning she would move wards: "It made me worse I think... more switchy because I think the more stressed I got... the more dissociative... so I'd lose more time". Similar accounts suggested that although dissociative experiences were recognised conditions by the participants and most ward staff, the approach of some staff seemed to exacerbate the extent to which participants would dissociate. 
Dissociative Experiences and Therapeutic Relationships on Wards

In summary, within the data was a phenomenon of a ricochet effect for participants, in that when one alter was unsettled, the whole person felt the anxiety and discomfort in different ways, which could lead to further dissociative experiences as a familiar means of coping. Elsewhere in the literature relating to in-hospital treatment (Laird, McCance, McCormack, \& Gribben, 2015), it has been suggested that person-centred care is particularly important due to the vulnerability people feel on hospital wards. The current study highlights how vulnerability without person-centred care can lead to further dissociation.

\section{2: Staff understanding of the internal system and the importance of parts' own}

names - "I wasn't addressed by my own [alter's] name at all." (Sam)

Positive relationships could develop if staff could recognise alters and support the whole person through dissociative experiences. For instance, Hermione explained how perceived understanding opened channels of communication: "you felt you could talk to someone that was somewhat... trained". However, participants with younger parts often found that staff did not recognise how to support them. For example, Amelia had lost much control over her alters and struggled with instructions: "I didn't know who I was and whose legs they were... 'Stop asking all of me to walk'." The phenomenon of "all of me" was common within the data and an apparent challenge for staff. Although adult parts seemed to feel anger in the face of judgements, younger parts seemed to feel increasingly "vulnerable" (Ellie) and "distressed" (Sam), which may have added to participants' overall distress and use of dissociative coping strategies.

To add further complications to existing interpersonal difficulties, some participants found that staff could miss when they dissociated, as Hermione stated, "People don't know you're switching!” Within several accounts appeared a connection between being seen, recognised and known, which seemed to facilitate a sense of perceived understanding. 
Dissociative Experiences and Therapeutic Relationships on Wards

Conversely, when participants interpreted staff as being unaware, uninformed and as making judgements, participants seemed to feel unaccepted. Importantly, when dissociative experiences were met with understanding and calm by staff, participants reported feeling calmer themselves, and needing dissociative coping mechanisms less; Ashleigh discussed how: "having some control... it calmed me down, it was about having a choice." Therefore, although emotional regulation directly influenced the need for dissociation as found in other empirical studies (e.g. Powers, Cross, Fani, \& Bradley, 2015), it was the relational dynamics and emotional regulation of staff around the participants that enabled them to manage their emotions and dissociation.

\section{Theme 2: Recognising, Meeting or Neglecting Interpersonal and Care Needs - "I discharged myself because my DID was becoming so unmanageable" (Amelia)}

All participants found their condition was unrecognised by some ward staff, which seemed to underlie some of the anxiety and wariness participants described: "that's the scary bit for me; I know there are probably more people stuck on a ward today who probably have DID who no one has probably picked up" (Ellie).

2.1: Staff's preconceptions and assumptions around normality- "they just label you. They don't ask, they just presume" (Mel)

The extraordinary lives and experiences of participants seemed to be unrecognised or disconcerting on occasion. For instance, Hermione discussed her construction of normality and reflected that: “most people don't experience themselves like I do". Similarly, Ashleigh reflected on how: "The illness was a protective factor in itself", which appeared strongly connected to her meaning making process around her experiences and her healing. Although Mel had some very difficult experiences following self-harm, she described how talking to a 
Dissociative Experiences and Therapeutic Relationships on Wards

researcher on one ward had helped her challenge perceived preconceptions of staff: "it helped because the nurses could see she asked me questions and wasn't put off. Just having conversations. It doesn't take very long. Find out a lot in 5 minutes."

Additionally, all participants reported that when their condition was not recognised appropriately, they felt increasingly judged, misunderstood and consequently more vulnerable. Ellie explained how having a support worker with her on a physical health ward influenced how other patients responded to her too: "Some of them [patients] would never speak to me because they must have wondered what on earth was going on". It has been suggested in the empirical literature that peer support from fellow patients can be experienced as very healing (Bradstreet, 2006). However, because Ellie was admitted and supervised on the health ward, she felt unable to connect with other ward patients, which appeared to add to her sense of being too different and an additional environmental stressor.

2.2: Meeting and neglecting the relational needs of the internal system - "I wanted them to make decisions with me, rather than for me.” (Ellie)

All participants reported some positive relational experiences with staff, through which staff tried to meet their needs. Claire explained how: "you can talk through your problems or things that are worrying you... I didn't know my key nurse [on another ward]”. Claire also explained how the staff in her last hospital "Just acted normally... they spoke to you on a normal level". Correspondingly, Sam reflected on talking with a psychiatrist: "First time asked what's going on for me! He said he got all the time.” Being heard seemed closely associated with being believed, recognised and accepted. This may have been particularly resonant for the participants who had experienced abuse as children, as disbelief and being unheard were likely dynamics that had previously caused much distress (Ullman, 2002). Finally, Ashleigh described a derealisation experience through which she felt understood, as 
she described: "her [nurse's] face had morphed and frightened me. I explained about her face changing... she arranged to have someone else check me at night”. Ashleigh's account highlights the sensitivity that some ward staff demonstrated, which may have also signalled compassion and therefore nurtured collaboration and understanding.

However, Ellie described how she found staff hard to relate to when they did not address her directly: “I didn't feel as though I wanted to engage with... because they weren't engaging with me". Participants provided numerous examples of how their experiences of relationships were influenced by the environment. There could be rapid changes in how participants experienced staff and themselves, individually and as they perceived they were seen through the eyes of the staff. This multiple perspective on self-perception and perceiving others connects with the aforementioned work of Liotti (2013). In the current study, relational difficulties were influenced by dissociating to alters, staff shift changes and further distressing dissociative experiences at night with fewer staff available, highlighting the apparent need for a member of staff to be "on the floor" (Hermione) whenever possible. Similarly, Mel and Ellie suggested that being on a one-to-one could be helpful if participants were rapidly switching because they were not able to maintain a coherent narrative around events themselves (Foa, Cashman, Jaycox, \& Perry, 1997). Therefore, having their experiences witnessed by another and recounted sensitively could be helpful in integrating current experiences, thus developing a complete narrative.

Finally, Mel recalled how she had disclosed abuse as a younger alter: "She [nurse] told me how I behaved and I couldn't remember any of that... I'd rather not have known. I couldn't understand how she [abuser] could do it to a baby." This example highlights how the process of memory recovery, whilst important to develop a self-narrative, can be detrimental to a person's wellbeing, despite novice therapists sometimes considering it helpful 
Dissociative Experiences and Therapeutic Relationships on Wards

(Loewenstein \& Wait, 2008), as seems to have happened in Mel's case. Experiences such as this highlight how important it is to promote the wellbeing of the central person. Similarly, Dillon, Johnstone, and Longden, recommend that "the therapist must work with " just enough of" the trauma at a time, so that each bit can be processed emotionally, physically and cognitively." (2012, p.152).

Theme 3: Between the Needs of the Internal System: navigating between "better on my own" and "someone to talk to" - "We [central persona and alters] usually say it's better to be lonely as you don't expect anything” (Sam)

The final set of phenomenological themes centre on how the participants experienced being surrounded by people on the ward in one sense, although experiencing the environment as fragmented, whilst simultaneously experienced themselves as very isolated and alone.

3.1: Working with dissociated parts, not around them - "I just want to be treated the same as every other patient on the ward, same empathy" (Amelia)

When staff reportedly neglected the needs of the participants' younger parts, experiences on the ward seemed considerably more difficult. For instance, Amelia explained how she had found it difficult to elicit communication with staff: "just because the seven year old part of me is there just now... people talked about me in front of me." Equally, Ellie noticed a younger alter had drawn a child-like picture. The staff did not tell Ellie what had happened, although she was aware how their "attitudes and responses was different", which led her to "feeling uncomfortable and wanting to leave hospital". Interestingly, the participants discussed wanting staff to relate to their younger or detached parts and older parts in similar ways, with empathy and positive communication. However, they also recognised that their younger or detached parts needed more sensitivity at times. Therefore, 
Dissociative Experiences and Therapeutic Relationships on Wards

there appeared a phenomenon of participants wanting relational care to be the same whilst different, which seemed connected to participants' difficulties in integrating their varying needs and preferences at times.

Similarly, Hermione explained how difficult it could be to experience certain dissociative phenomenon in the company of staff who did not recognise her dissociative experiences: "I was... frozen... for an hour and a half... they don't care... they're not informed... they don't know that that's a terrifying place to be... little parts crying... teenage parts angry". Experiences of these parasympathetic states, thought to be used in extremely threatening situations when active responses could elicit more harm (Baldwin, 2013), could signify how Hermione perceived the ward as "terrifying", thus relying on this type of dissociation.

Accounts from all participants suggested the hope for help but lack of support from some staff could enhance feelings of helplessness and loneliness: "That's worse. They're supposed to be helping you, expectations they can fix us [self and alters]" (Sam). Therefore, this may be further evidence of how past experiences of harmful attachment figures in authority may be a particularly powerful parallel process within a ward environment. This process may also be reminiscent of the trauma re-enactment processes discussed in Schimmenti and Caretti, (2014). This process of experiencing a frightening but needed attachment figure has been termed: "fright without solution," as the attachment figure encapsulates both potential danger and comfort (Main \& Hesse, 1990, p.163). Consequently, desires for closeness through connection and safety through being alone conflict, causing further distress (Liotti, 2013), and as reported in this study, further dissociation as a coping strategy. 
Dissociative Experiences and Therapeutic Relationships on Wards

\section{2: Forgetting, remembering and reorganising information and experiences -}

“don't remember getting stitched up, must have dissociated, I come round and was on the ward and they [ward staff] were a nightmare" (Mel)

Memory loss could cause distress in the form of anxiety, such as that explained by Ellie, "what have I done, have I done anything wrong, have I embarrassed myself?" However, memory losses could also result in physical harm or perpetuating abusive dynamics, as Mel described: "They say if you can do that to yourself [self-injury], you can be stitched without anaesthetic." Hermione added that due to her unrecognised memory difficulties, she missed her medication on the ward, which included her diabetes medication: "'you have to be responsible for your own medication'... when you're even more in a distressed state, when you're in a bloody hospital, it's ridiculous!"

Additionally, most of the participants reported having a designated nurse and described confusion around recognising them because of difficulties. These difficulties could be indicative of visual and auditory recognition complications, which may tentatively be connected to more generalised cognitive avoidance recognised in dissociative conditions (Stovall-McClough \& Cloitre, 2006). In terms of participants' cognitive functioning on the wards, numerous examples emerged from the data of participants experiencing delayed memory difficulties (as found in Giesbrecht, Lilienfield, Lynn, \& Merckelbach, 2008), perhaps unsurprisingly considering the cognitive interference of voices, time losses and alters reported. Consequently, there appeared to be a need for repetition, reminders and predictability.

Furthermore, Amelia described how she needed her dissociative coping strategies to manage her experiences on the ward: "I was happy to allow my 13 year old who swears continually to tell them where to go, it was so frustrating”. Additionally, Mel, Ellie and Sam 
Dissociative Experiences and Therapeutic Relationships on Wards

shared similar experiences. These experiences of alters managing threatening situations appeared connected to the drama triangle postulated by Liotti (2004), through which the self and others are viewed as a rescuer, persecutor and victim. It appears from the data as though alters could become rescuers when the main persona became the victim, with staff viewed as the perpetrator. This pattern seems similar to the victim-based schemas found in the empirical study of McAllister et al. (2001), which add complexity to the interpersonal relationships between patients and ward staff, until new roles can be developed through accepting and empathic therapeutic relationships.

\section{Concluding Discussion}

Trauma-informed person-centred care seems particularly crucial for people who require personalised grounding techniques, familiarity, and nurturing relationships for selfregulation and affective-regulatory strategies (ISSTD, 2011; Laird, McCance, Mccormack, \& Gribben, 2015). As people experiencing dissociation are at a higher risk of self-injury, suicide attempts, mental health sections and other unplanned hospital admissions (Foote, Smolin, Neft, \& Lipschitz, 2008), this is a client group in need of appropriately tailored ward-based services. Further, participants identified that in order to develop positive relationships, staff needed to be calm, humorous, comforting, nurturing, and friendly, provide choices, and be approachable and available. Although grounding techniques have been found helpful in DID research (Brand, Loewenstein, and Spiegel, 2014; Dorahy et al., 2014; ISSTD, 2011), Claire and Ashleigh, who did not report having a DID diagnosis, also recommended individualised grounding techniques. Therefore, people with a range of dissociative conditions may benefit from similar guidelines that promote the importance of safety, stabilisation and a personcentred approach to care. 
Dissociative Experiences and Therapeutic Relationships on Wards

Through developing an environment that feels safe, structured and nurturing, combined with ward staff providing empathy, warmth and acceptance around dissociative experiences, participants could feel less distressed, which reduced their need to rely on dissociative coping strategies. To conclude, a consistent approach to care is particularly important for people experiencing dissociation due to the disconnections experienced in relationships and specific needs around predictability and integration.

Future research could explore whether men have similar experiences to the women in this study. For instance, it has been found there are existing gender differences in diagnosis and treatment (Shevlin, Murphy, \& Read, 2015); specifically that women report increased negative experiences relating to staff communication around medication and discharge (Elliott et al., 2012), as was demonstrated in the present study. Additionally, some of the experiences participants could not discuss in detail were experienced by alters, who may have had an independent perspective (Nijenhuis \& Van der Hart, 2011). Research with central personas and alters could develop flexible guidance, which could enhance the quality of wrap-around interventions for ward-based care with alters. Finally, due to the time disruptions and related complexities these subjective perceptual difficulties might pose for clinicians and researchers (Todd, Simpson, \& Murray, 2010), it is unclear at this stage what the impact of dissociation is for IPA research. 
Dissociative Experiences and Therapeutic Relationships on Wards

\section{References}

Baldwin, D.V. (2013). Primitive mechanisms of trauma response: An evolutionary perspective on trauma-related disorders. Neuroscience and Biobehavioral Reviews, 37(8), 1549-1566. doi: 10.1016/j.neubiorev.2013.06.004

Bedard-Gilligan, M., \& Zoellner, L.A. (2012). Dissociation and memory fragmentation in post-traumatic stress disorder: An evaluation of the dissociative encoding hypothesis. Memory, 20(3), 277-299. doi: 10.1080/09658211.2012.655747

Bhaskar, R. (1993). Dialectic: the pulse of freedom, London; New York: Verso. ISBN 0$86091-583-2$

Bradstreet, S. (2006). Harnessing the 'lived experience'. Formalising peer support approaches to promote recovery. The Mental Health Review, 11(2), 33-37. ISSN: 1361-9322

Braehler, C., Valiquette, L., Holowka, D., Malla, A. K., Joober, R., Ciampi, A., \& King, S. (2013). Childhood trauma and dissociation in first-episode psychosis, chronic schizophrenia and community controls. Psychiatry research, 210(1), 36-42. doi: 10.1016/j.psychres.2013.05.033)

Brand, B.L., Loewenstein, R.J., \& Spiegel, D. (2014). Dispelling Myths About Dissociative Identity Disorder Treatment: An Empirically Based Approach. Psychiatry, 77(2), 169189. doi: $10.1521 /$ psyc.2014.77.2.169

Brown, R.J., Schrag, A., \& Trimble, M. R. (2005). Dissociation, childhood interpersonal trauma, and family functioning in patients with somatization disorder. American Journal of Psychiatry, 162(5), 899-905. PMID: 15863791 
Dissociative Experiences and Therapeutic Relationships on Wards

Carlson, E.M., \& Putnam, F.W. (1986). Development, reliability, and validity of a dissociation scale. Journal of Nervous and Mental Disease, 174(12), 727-735. ISSN: 0022-3018

Dillon, J., Johnstone, L., \& Longden, E. (2012). Trauma, Dissociation, Attachment \& Neuroscience: A new paradigm for understanding severe mental distress. The Journal of Critical Psychology, Counselling and Psychotherapy, 12(3), 145-155. URI: http://repository.liv.ac.uk/id/eprint/1764187

Dorahy, M.J., Brand, B.L., Şar, V., Krüger, C., Stavropoulos, P., Martínez-Taboas, A., Lewis-Fernández, R., \& Middleton, W. (2014). Dissociative identity disorder: An empirical overview. Australian \& New Zealand Journal of Psychiatry, 48(5), 402417. doi: $10.1177 / 0004867414527523$

Dutra, L., Bureau, J., Holmes, B., Lyubchik, A., \& Lyons-Ruth, K. (2009). Quality of early care and childhood trauma: a prospective study of developmental pathways to dissociation. The Journal of nervous and mental disease, 197(6), 383-90. doi: 10.1097/NMD.0b013e3181a653b7

Elliott, M.N., Lehrman, W.G., Beckett, M.K., Goldstein, E., Hambarsoomian, K., \& Giordano, L.A. (2012). Gender Differences in Patients' Perceptions of Inpatient Care. Health Services Research, 47(4), 1482-1501. doi: 10.1111/j.1475-6773.2012.01389.x

Foa, E.B., Cashman, L., Jaycox, L.H., \& Perry, K. (1997). The validation of a self-report measure of PTSD: The PTSD Diagnostic Scale (PDS). Psychological Assessment, 9, 445-451. doi: 10.1037/1040-3590.9.4.445 
Dissociative Experiences and Therapeutic Relationships on Wards

Foote, B., Smolin, Y., Neft, D.I., \& Lipschitz, D. (2008). Dissociative disorders and suicidality in psychiatric outpatients. The Journal of nervous and mental disease, 196(1), 29-36. doi: 10.1097/NMD.0b013e31815fa4e7

Frank, A.F., \& Gunderson, J.G. (1990). The Role of the Therapeutic Alliance in the Treatment of Schizophrenia Relationship to Course and Outcome. The archives of General Psychiatry, 47(3), 228-236. doi:10.1001/archpsyc.1990.01810150028006

Giesbrecht, T., Lilienfield, S.O., Lynn, S.J., \& Merckelbach, H. (2008). Cognitive Processes in Dissociation: An Analysis of Core Theoretical Assumptions. Psychological Bulletin, 134(5), 617-647. doi: 10.1037/0033-2909.134.5.617

Gill, S. (2010). The therapist as psychobiological regulator: Dissociation, affect attunement and clinical process. Clinical Social Work Journal, 38(3), 260-268. Doi: $10.1007 / \mathrm{s} 10615-009-0213-5$

Hefferon, K., \& Gil-Rodriguez, E. (2011). Reflecting on the rise in popularity of interpretive phenomenological analysis. The Psychologist, 24(10), 756-759. Retrieved from http://www.thepsychologist.org.uk/archive/archive_home.cfm?volumeID=24\&edition ID $=206 \&$ ArticleID $=1930$

Hirakata, P. (2009). Narratives of Dissociation: Insights into the Treatment of Dissociation in Individuals Who Were Sexually Abused as Children. Journal of Trauma \& Dissociation, 10(3), 297-314. doi: 10.1080/15299730902956804

Holmes, E., Brown, R.J., Mansell, W., Fearon, R., Hunter, E., Frasquilho, F., \& Oakley, D. (2005). Are there two qualitatively distinct forms of dissociation? A review and some 
Dissociative Experiences and Therapeutic Relationships on Wards

clinical implications. Clinical Psychology Review, 25, 1-23. doi:

10.1016/j.cpr.2004.08.006

International Society for the Study of Trauma and Dissociation. (2011). Guidelines for treating dissociative identity disorder in adults, third revision. Journal of Trauma \& Dissociation, 12, 115-187. doi: 10.1080/15299732.2011.537247

Laird, E.A., Mccance, T., Mccormack, B., \& Gribben, B. (2015). Patients' experiences of inhospital care when nursing staff were engaged in a practice development programme to promote person-centredness: A narrative analysis study. International Journal of Nursing Studies, 32(1). doi: 10.1016/j.ijnurstu.2015.05.002

Liotti, G., (2004). Trauma, dissociation, and disorganized attachment: Three strands of a single braid. Psychotherapy Theory Research \& Practice, 41(4), 472-486. doi: $10.1037 / 0033-3204.41 .4 .472$

Liotti, G. (2013). Phobias of Attachment-Related Inner States in the Psychotherapy of Adult Survivors of Childhood Complex Trauma. Journal of Clinical Psychology, 69(11), 1136-1147. doi: $10.1002 /$ jclp.22041

Lyons-Ruth, K., Dutra, L., Schuder, M.R., \& Bianchi, I. (2006). From Infant Attachment Disorganization to Adult Dissociation: Relational Adaptations or Traumatic Experiences? The Psychiatric Clinics of North America, 29(1), 63-86. doi:10.1016/j.psc.2005.10.011

Main, M., \& Hesse, E.D. (1990). Parents' unresolved traumatic experiences are related to infant disorganized attachment status: Is frightened and/or frightening parental behavior the linking mechanism? In Greenberg, M., Cichetti, D., \& Cummings, M. 
Dissociative Experiences and Therapeutic Relationships on Wards

(Eds), Attachment in the Preschool Years. Chicago: Chicago University Press. ISBN: 9780226306308

McAllister, M., Higson, D., McIntosh, W., O'Leary, S., Hargreaves, L., Murrell, L., Mullen, V., Lovell, F., Kearney, J., Sammon, D., Woelders, S., Adams, T., Davies-Cotter, D., Wilson, J., \& O'Brien, J. (2001). Dissociative identity disorder and the nurse-client relationship in the acute care setting: An action research study. Australian and New Zealand Journal of Mental Health Nursing, 10(1), 20-32. doi: 10.1046/j.14400979.2001.00188.x

Merckelbach, H., Devilly, G.J., \& Rassin, E. (2002). Alters in dissociative identity disorder: Metaphors or genuine entities? Clinical Psychology Review, 22(4), 481-497. doi: $10.1016 / \mathrm{S} 0272-7358(01) 00115-5$

Mikulincer, M., Shaver, P.R., \& Berant, E. (2013). An Attachment Perspective on Therapeutic Processes and Outcomes. Journal of Personality, 81(6), 606-616. doi: $10.1111 / \mathrm{j} .1467-6494.2012 .00806 . x$

Moskowitz, A. (2004). Dissociation and Violence: A Review of the Literature. Trauma, Violence and Abuse, 5(1), 21-46. doi: 10.1177/1524838003259321

Nijenhuis, E.R.S. (2008). Dissociation and self-consciousness. International Society for the Study of Dissociation and Trauma, Members' Clinical Corner.

Nijenhuis, E.R.S., Van der Hart, O. (2011). Defining dissociation in trauma. Journal of Trauma and Dissociation, 12(4), 469-73. doi: 10.1080/15299732.2011.570233 
Dissociative Experiences and Therapeutic Relationships on Wards

Pietkiewicz, I., \& Smith, J.A. (2014). A practical guide to using Interpretative Phenomenological Analysis in qualitative research psychology. Czasopismo Psychologiczne - Psychological Journal, 20(1), 7-14. doi: 10.14691/CPPJ.20.1.7

Powers, A., Cross, D., Fani, N., \& Bradley, B. (2015). PTSD, emotion dysregulation, and dissociative symptoms in a highly traumatized sample. Journal of psychiatric research 61, 174-179. doi: 10.1016/j.jpsychires.2014.12.011

Schimmenti, A., \& Caretti, V. (2014). Linking the overwhelming with the unbearable: Developmental Trauma, Dissociation, and the Disconnected Self. Psychoanalytic Psychology. doi: 10.1037/a0038019

Shevlin, M., Murphy, J., \& Read, J. (2015). Testing complex hypotheses using secondary data analysis: is the association between sexual abuse and psychosis moderated by gender in a large prison sample? Journal of Criminal Psychology, 5(2), 92-98. doi: 10.1108/JCP-02-2015-0009

Smith, J.A. (2011). Evaluating the contribution of interpretative phenomenological analysis. Health Psychology Review, 5(1), 9-27. doi: 10.1080/17437199.2010.510659

Strachan, H. (2011). The NMAHP Contribution to Quality Caring - The Concept, Behaviours, Influences and Impact. NMAHP Quality Councils. Retrieved from: http://www.knowledge.scot.nhs.uk/media/CLT/ResourceUploads/1012667/Caring\%2 0-\%20The\%20Concept,\%20Behaviours,\%20Influences\%20and\%20Impact.pdf

Stovall-McClough, K.C., \& Cloitre, M. (2006). Unresolved Attachment, PTSD, and Dissociation in Women with Childhood Abuse Histories. Journal of Consulting and Clinical Psychology, 74(2), 219-228. ISSN: 0022-006X 
Dissociative Experiences and Therapeutic Relationships on Wards

Todd, D., Simpson, J., \& Murray, C. (2010). An interpretative phenomenological analysis of delusions in people with Parkinson's disease. Disability and rehabilitation, 32(15), 1291-9. doi: 10.3109/09638280903514705

Ullman, S.E. (2002). Social Reactions to Child Sexual Abuse Disclosures: A Critical Review, Journal of Child Sexual Abuse, 12(1), 89-121. doi: 10.1300/J070v12n01_05 